\title{
ТОПОГРАФО-ГЕОДЕЗИЧЕСКОЕ И КАРТОГРАФИЧЕСКОЕ ОБЕСПЕЧЕНИЕ АРКТИЧЕСКОЙ ЗОНЫ РОССИЙСКОЙ ФЕДЕРАЦИИ
}

\author{
М.Г.МУСТАФИН ${ }^{1}$, В.Н.БАЛАНДИН ${ }^{2}$, М.Я.БРЫНЬ ${ }^{3}$, А.Ю.МАТВЕЕВ ${ }^{4}$, И.В.МЕНЫШИКОВ ${ }^{2}$, Ю.Г.ФИРСОВ ${ }^{2}$ \\ ${ }_{1}^{1}$ Санкт-Петербургский горный университет», Санкт-Петербург, Россия \\ ${ }^{2}$ Федеральный научно-технический центр геодезии, картографии и инфраструктуры пространственных данных, \\ Санкт-Петербург, Россия \\ ${ }^{3}$ Петербургский государственный университет путей сообщения, Санкт-Петербург, Россия \\ ${ }^{4}$ АО «Аэрогеодезия», Санкт-Петербург, Россия
}

\begin{abstract}
Предложен вариант проекта концепции топографо-геодезического и картографического обеспечения Арктической зоны РФ на основе использования современных средств и методов, а также приведено ее содержание. Последовательно изложены результаты внедрения в Арктике разработок, выполненных с участием авторов в 1961-1967 и 1975-1992 годах. Подчеркивается стратегическое значение и большое внимание государственных структур к освоению Арктической зоны. Приведены ключевые моменты развития топографогеодезического и картографического обеспечения для этого региона. Показана роль ведущих научноисследовательских институтов в этом процессе. Предлагаемая концепция включает шесть этапов. При создании плановой геодезической основы авторы рекомендуют альтернативный инновационный алгоритм определения высоты $H$ без предварительного вычисления широты $B$ с использованием только спутниковых измерений. Рассмотрен чрезвычайно важный вопрос о преобразовании геодезических координат $B, L$ в плоские прямоугольные координаты $x, y$. Для территории РФ предложены новые разработки, использующие данные спутниковых определений, новый подход к определению нормальных высот и преобразования пространственных прямоугольных координат в плоские прямоугольные координаты, необходимые для целей картографирования. Показаны необходимые положения, которые должна содержать нормативно-техническая документация по топографической сьемке шельфа. Показана важность реализации концепции в связи с определением внешней границы континентального шельфа Северного Ледовитого океана.
\end{abstract}

Ключевые слова: топографо-геодезическое и картографическое обеспечение Арктики; концепция; координаты; преобразование координат; спутниковые определения

Как цитировать эту статью: Топографо-геодезическое и картографическое обеспечение Арктической зоны Российской Федерации / М.Г.Мустафин, В.Н.Баландин, М.Я.Брынь, А.Ю.Матвеев, И.В.Меньшиков, Ю.Г.Фирсов // Записки Горного института. 2018. Т. 232. С. 375-382. DOI: 10.31897/PMI.2018.4.375

Введение. Арктическая зона Российской Федерации занимает значительную часть ее площади, которая охватывает как сухопутные территории, так и морские акватории, включающие шельфовые области Северного Ледовитого океана (СЛО). Несмотря на огромную площадь Арктики РФ, она намного слабее обеспечена в топографо-геодезическом и картографическом отношении, чем остальная территория РФ. Учитывая стратегическое значение арктических регионов РФ в настоящем и в перспективе (добыча и транспортировка нефти и газа, трасса Северного морского пути, установление внешней границы континентального шельфа морей СЛО в пределах территорий РФ, оборона северных рубежей России и др.), чрезвычайно актуальной является проблема разработки концепции топографо-геодезического и картографического обеспечения Арктической зоны РФ и, естественно, ее реализация. Без решения этой задачи невозможно воплощение большинства научных и практических проектов на территории Арктики. В статье предложен вариант проекта концепции.

Методология. Профессиональное геодезическое обеспечение сухопутных арктических регионов СССР началось в 20-30-х годах прошлого столетия, в основном, силами топографогеодезических предприятий, расположенных на Крайнем Севере. Планово-высотные геодезические сети создавались традиционными геодезическими методами (астрономические наблюдения, триангуляция, трилатерация, полигонометрия, геометрическое нивелирование, гравиметрия). Топографическая съемка осуществлялась тахеометрическим и мензульным способами, в дальнейшем, главным образом, с помощью аэрофотосъемки.

Начало активному морскому освоению Арктики положило создание в 1932 г. Главного управления Северного морского пути и в его составе «Гидрографического предприятия». Предприятием создано свыше 800 адмиралтейских номеров морских навигационных карт морей СЛО и сотни различных средств навигационного оборудования трассы Северного морского пути [1].

Начиная с 60-х годов прошлого столетия для определения плановых координат центров фотографирования аэроснимков стали применяться радиогеодезические системы (РГС), в частности 
Топографро-геодезическое и картографическое обеспечение Арктической зоны...

«Поиск» [5]. В 1960-1961 годах Всесоюзным маркшейдерским трестом «Союзмаркштрест» (СМТ) совместно с Всесоюзным научно-исследовательским геофизическим институтом (ВНИИГеофизика) и Всесоюзным научно-исследовательским маркшейдерским институтом (ВНИМИ) была разработана методика использования РГС «Поиск» для картографирования местности [5]. Одновременно составлен алгоритм вычисления координат определяемых точек путем решения гиперболической засечки. Алгоритм реализован в программном продукте для ЭВМ «Урал-1». По своим показателям программа не уступала зарубежным аналогам, разработанным применительно к РГС «Шоран» (США) и РГС «Декка» (Англия). Аэрофотосьемка проводилась совместно с радиогеодезическими измерениями по каркасным маршрутам, проложенным на объекте.

Фотограмметрические измерения выполнялись преимущественно на стереокомпараторах фирмы «Карл Цейс, Йена». По контурным точкам - «камеральным опознакам» каркасных маршрутов аналитическим методом А.Н.Лобанова строились свободные сети пространственной фототриангуляции, протяженностью до 200 стереопар (шесть опознаков на стереопару). В сети включались также полевые высотные (баронивелирование) опознаки, опорные пункты (попадающие на маршруты). По плановым координатам и высотам фотографирования с использованием результатов вычислений пространственной фототриангуляции определялись плановые координаты и высотные отметки «камеральных опознаков» на каркасных маршрутах. Полученные планово-высотные опознаки использовались для дальнейшего составления топографических карт по известной методике.

Наилучших результатов внедрения радиогеодезического метода в практику картографического обеспечения арктических сухопутных регионов СССР достигла Ленинградская экспедиция СМТ. Работы выполнены в 1961-1967 годах на пяти объектах площадью 72,8 тыс. км². Всего определены координаты свыше 10 тыс. центров фотографирования, составлено около 2 тыс. трапеций карт масштаба 1:25000.

Созданные топографические карты арктических регионов России с успехом использовались и продолжают использоваться при разведке и эксплуатации месторождений полезных ископаемых (нефть, газ, алмазы, золото) и решении других вопросов.

Созданным в 1975 г. отделом съемки шельфа (ОСШ) и Мирового океана Центрального научно-исследовательского института геодезии, аэросъемки и картографии (ЦНИИГАиК) (в настоящее время отдел съемки шельфа Центра геодезии, картографии и инфраструктуры пространственных данных) было предложено новое направление деятельности топографо-геодезических предприятий ГУГК - выполнение топографической съемки шельфа, целью которой являлось создание топографических карт шельфа [12]. Отличие этих карт от морских навигационных состоит в следующем: вместо проекции Меркатора используется картографическая проекция Гаусса; рельеф дна дается в горизонталях, а не в изобатах; карты более информативные и многоцелевые.

Отдел съемки шельфа был ориентирован на выполнение следующих задач (в основном в акватории СЛО и его побережья): разработка нормативно-технической документации по топографо-геодезической съемке шельфа; участие в разработке технических средств; техническое руководство предприятиями ГУГК по топографической съемке шельфа и сопровождение созданных ЦНИИГАиК нормативных документов и технических средств. С поставленными задачами в период 1975-1991 годов ОСШ успешно справился. Впервые была создана необходимая для топографической съемки шельфа нормативно-техническая документация (инструкции, руководства, руководящие технические материалы (РТМ), условные знаки, нормы выработки и др.). Все документы разработаны в рамках научно-исследовательских тем и утверждены ГУГК.

В 1977 г. впервые в нашей стране в ЦНИИГАиК создана автоматическая линия сбора и первичной обработки информации съемки шельфа АВТОКООРДИНАТОР [5], предназначенная для использования в самолетном и судовом вариантах.

В 1979-1980 годах ПО «Северо-Западная Аэрогеодезия» совместно с ЦНИИГАиК созданы малогабаритный эхолот-регистратор ЭРА-1 и измеритель скорости звука в морской воде МИС-1. На момент создания приборов отечественных аналогов не существовало. Патентный поиск по аналогам ведущих стран (США, Англия, Франция, Германия, Япония) показал некоторое преимущество разрабатываемых на тот период времени приборов ЭРА-1 и МИС-1. 
Топографро-геодезическое и картографрическое обеспечение Арктической зоны...

Под методическим руководством ЦНИИГАиК предприятиями ГУГК выполнен значительный объем топографической съемки шельфа в морях СЛО (Баренцевом, Белом, Карском, Лаптевых, Восточно-Сибирском). Материалы выполненной топографической съемки послужили основой для создания топографических карт шельфа (несколько сотен листов масштабов 1:10 000 и $1: 25000)$ [7].

Кроме разработки и внедрения средств и методов топографической съемки шельфа авторы участвовали в выполнении морской геофизической съемки с помощью РГС «Поиск» на нефтегазовых месторождениях Приразломное и Штокмановское в Баренцевом море. Необходимо отметить выполненные исследования по прогнозированию сдвижений и разломов земной почвы под воздействием выработок полезных ископаемых (в основном угля), при которых происходит деформация координатной основы в данном районе. Прогноз позволяет оптимально выбрать местоположение пунктов геодезической сети. Методика, разработанная во ВНИМИ, успешно внедрена в ряде промышленных районов Арктики, в том числе в Воркутинском угольном бассейне [8, 9].

Начиная с 1991 г. в связи с экономической ситуацией в стране работы ГУГК по топографической съемке шельфа прекратились, а объем работ по гидрографической съемке резко сократился. Сегодня гидрографическая съемка осуществляется в основном частными фирмами на локальных акваториях шельфа (порты, морские буровые платформы, морские нефтегазомагистрали и т.д.).

Значительная часть технических средств (радиогеодезические системы, радиодальномеры и др.) и традиционных методов (триангуляция, астрономические наблюдения и др.) выполнения топографо-геодезических работ морально устарела. Требуется коренной пересмотр концепции топографо-геодезического и картографического обеспечения территорий РФ на основе использования современных технических средств (спутниковые приемники, электронные тахеометры, традиционная и цифровая аэрофотосъемка, многолучевые эхолоты и др.) и прогрессивных технологий (создание спутниковых геодезических сетей, спутниковое нивелирование, электронная тахеометрия и др.). Особенно актуальна эта проблема для Арктики, которая чрезвычайно слабо обеспечена в топографо-геодезическом и картографическом отношении.

В один из возможных вариантов концепции предлагается включить следующие элементы:

- создание плановой спутниковой геодезической основы;

- преобразование геодезических координат в плоские в широкой координатной зоне;

- определение аномалий высот спутниковым методом при морском ледовом промере;

- картографическое обеспечение Арктики;

- обновление нормативно-технической документации;

• исследования по определению внешней границы континентального шельфа в пределах полярных владений РФ.

Создание плановой геодезической спутниковой основы. Плановая спутниковая геодезическая основа создается в соответствии с основополагающим нормативным документом «Основные положения о государственной геодезической сети Российской Федерации». ГКИНП (М.: ЦНИИГАиК, 2004. 14 с.)

На каждом определяемом пункте спутниковой геодезической сети автономно измеряются пространственные прямоугольные координаты $X, Y, Z$ [11], для их использования в картографических целях они должны быть преобразованы в геодезические координаты: $B$ (широта), $L$ (долгота), $H$ (высота). При этом наиболее просто определяется долгота $L$, а наиболее сложно - широта $B$. В этом случае, как правило, необходимо выполнение нескольких итераций. Высота $H$ вычисляется после нахождения широты $B$.

Авторами разработан альтернативный инновационный алгоритм определения высоты $H$ без предварительного вычисления широты $B$ с использованием только спутниковых измерений $X$, $Y, Z[4,10]$ :

$$
H=\left[D-\frac{b}{\sqrt{1-e^{2}\left(\frac{S}{D}\right)^{2}}}\right] \cos \left(e^{2} \rho \frac{S Z}{D^{2}}\right),
$$


Топографро-геодезическое и картографическое обеспечение Арктической зоны...

где $D=\sqrt{S^{2}+Z^{2}} ; b$ - малая полуось используемого земного эллипсоида; $e^{2}-$ квадрат эксцентриситета эллипсоида; $S=\sqrt{X^{2}+Y^{2}} ; \rho=57,29577951^{\circ}$ (const).

Отечественных и зарубежных аналогов алгоритма (1) нет. С учетом полученной высоты $H$ вычислим широту:

$$
\operatorname{tg} B=\frac{Z-H e^{2} \sin B_{0}}{\left(1-e^{2}\right) S}
$$

где $\operatorname{tg} B_{0}=\frac{Z}{\left(1-e^{2}\right) S}$.

Долгота $L$ определяется по формуле $L=\operatorname{arctg} Y / X$. Для дальнейших вычислений необходима разность долгот: $l=L-L_{0}$ (здесь $L_{0}$ - долгота осевого меридиана).

Преобразование геодезических координат $B, l$ в плоские прямоугольные $x, y$, необходимые для картографирования, были предложены в 1820-1830 годах немецким математиком К.Ф.Гауссом [4]. До настоящего времени формулы вычисления плоских прямоугольных координат, несмотря на многообразные инварианты, практически остались неизменными и достаточно громоздкими.

Предлагаются следующие альтернативные алгоритму Гаусса формулы вычисления прямоугольных координат в 6-градусной зоне по известным геодезическим координатам:

$$
\begin{gathered}
x=X+\Delta x ; X=\frac{R_{\ni}}{\rho^{0}} \operatorname{arctg}\left[\frac{R_{\ni} \sqrt{1-e^{2}}}{a} \cos \left(\frac{1}{6} \cos B\right) \operatorname{tg} B\right] q ; \\
\Delta x=\frac{N}{\rho}\left[\operatorname{arctg}\left(\frac{\operatorname{tg} B}{\cos t}\right)-B\right] t ; \\
y=\frac{N}{\sqrt{V}} \operatorname{arth}(\sqrt{V} \cos B \sin l),
\end{gathered}
$$

где $X$ - длина дуги осевого меридиана; $\Delta x=(x-X)$ - разность абсцисс; $R_{э}=\frac{3}{4}(a+b)-\frac{1}{2} \sqrt{a b}-$ эквивалентный радиус кривизны эллипсоида [4]; $e^{2}, e^{2}-$ квадраты первого и второго эксцентриситетов эллипсоида; $a, b-$ большая и малая полуоси эллипсоида; $q=\cos \left[0,003 \sin ^{2} B\right] ; N=\frac{a}{W}-$ радиус кривизны первого вертикала; $t=1,000014 \cos ^{4} B ; V=\sqrt{1-e^{2} \cos ^{2} B}$ и $W=\sqrt{1-e^{2} \sin ^{2} B}-$ основные сфероидические функции [4] (функции $W, V$ введены К.Ф.Гауссом).

Преобразование геодезических координат в плоские прямоугольные в широкой координатной зоне. В Арктической зоне РФ значительная часть стратегических линейных коммуникаций (магистральные наземные и подводные нефтегазопроводы, трасса Северного Ледовитого океана и др.) имеют долготную протяженность, т.е. проходят через несколько 6-градусных координатных зон картографической проекции Гаусса. Территория РФ расположена в двадцати шести 6-градусных координатных зонах - от V зоны (западная геодезическая долгота $L=24^{\circ}$ ) до XX зоны (восточная геодезическая долгота $L=180^{\circ}$ ). Поэтому линейная магистраль часто располагается в разных координатных зонах. Для получения плоских прямоугольных координат различных точек магистрали, требуемых для картографирования, необходимо их достаточно трудоемкое преобразование из одной 6-градусной зоны в другую.

На этом основании вопрос преобразования геодезических координат $B, L$, получаемых в настоящее время по спутниковым координатам $X, Y, Z$, в плоские прямоугольные координаты $x, y$ в единой координатной зоне является чрезвычайно актуальным.

Авторами предложен алгоритм преобразования геодезических координат:

$$
x=\frac{R_{19}}{\rho} \operatorname{arctg}\left(\frac{\operatorname{sh} q}{\cos t}\right)+\frac{R_{2 \ni}}{2 \rho}\left[\operatorname{arctg}\left(\frac{2 k \operatorname{sh} q \cos l}{1-t^{2}}\right)+\frac{0^{\circ}}{180^{\circ}}\right] ;
$$


Топографо-геодезическое и картографическое обеспечение Арктической зоны..

$$
y=R_{13} \operatorname{arth}\left(\frac{\sin l}{\operatorname{ch} q}\right)+\frac{R_{2 \ni}}{2 \rho} \operatorname{arth}\left(\frac{2 k \operatorname{ch} q \sin l}{1-t^{2}}\right),
$$

где $R_{1 э}=3430583,135$ м (для СК-42); $R_{2 э}=2936973,362$ м (для СК-42) (при этом $R_{1 э}+R_{2 э}=R_{\ni}=$ $=6367558,497 \mathrm{M}) ; q=\operatorname{arth}(\sin B)-e \operatorname{arth}(e \sin B) ; e=0,081813334$ (const); $k=1,003638604$ (эллипсоид Красовского); $t^{2}=k^{2}\left(\operatorname{sh}^{2} q+\sin ^{2} l\right)$.

Для территории РФ при использовании предложенного алгоритма выбран средний осевой меридиан с долготой

$$
L_{0}=\frac{1}{2}\left(24^{\circ}+180^{\circ}\right)=102^{\circ} .
$$

Положительные стороны использования единой зоны для всей территории РФ:

- не надо выполнять преобразования координат $x, y$ из зоны в зону;

- алгоритм, в отличие от известных, является безытерационным и не требует разложения в ряды;

- предложенный алгоритм может быть использован в приполярных зонах (до $B \leq 89,9^{\circ}$ );

- простота алгоритма, его реализация не представляет сложности при использовании 9-разрядного инженерно-научного микрокалькулятора (с гиперболическими функциями), что является невозможным для других достаточно сложных алгоритмов, предполагающих использование только персональных компьютеров и дорогостоящих отечественных и особенно иностранных программных продуктов;

- для определения координат $x, y$ некоторых удаленных объектов (включая объекты на островах СЛО) целесообразно использовать предложенный алгоритм, особенно полезным будет его применение для целей Министерства обороны России.

Определение аномалий высот спутниковым методом при морском ледовом промере. Как известно, аномалия высоты $\zeta$ представляет собой высоту квазигеоида над поверхностью эллипсоида [11]:

$$
\zeta=H-H^{\gamma},
$$

при этом значение $\zeta$ колеблется от -107 до +85 м.

Определение аномалий высот в море, особенно в высоких широтах шельфа Арктики, является достаточно актуальным. Следует отметить, что в морях и океанах поверхность геоида совпадает с поверхностью квазигеоида. Одним из видов морского картографирования является ледовый промер.

Учитывая, что $H=h+\zeta$, где $h$ - высота антенны, т.е. расстояние от центра приема спутниковых измерений до поверхности воды (геоид), не превышает 100 м, вместо формулы (1) без потери точности, можно использовать более простое выражение

$$
H=D-\frac{b}{{\sqrt{1-e^{2}\left(\frac{S}{D}\right)^{2}}}^{2}} .
$$

Нормальная высота $H^{\gamma}$ в данном случае равна измеренной высоте антенны, поэтому

$$
\zeta=D-\frac{b}{\sqrt{1-e^{2}\left(\frac{S}{D}\right)^{2}}}-h .
$$

Предложенный подход является инновационным и не имеет отечественных и зарубежных аналогов. Он особенно перспективен для использования в арктических регионах РФ на побережье СЛО. С помощью спутникового нивелирования возможно создание и сгущение сети нормальных высот с точностью не ниже нивелирования IV класса. При этом необходимо учитывать средний уровень морей СЛО согласно методике по учету колебаний уровня моря с помощью уровенных постов, изложенной в [12]. Целесообразно определение координат уровенных постов на всем побережье спутниковым методом. В авиадесантном режиме применение данной методики позволит значительно снизить затраты, ввиду отсутствия гравиметрических измерений. 
Топографро-геодезическое и картографрическое обеспечение Арктической зоны...

Таким образом, в этом случае побережье СЛО используется как исходная уровенная поверхность, поскольку уровенные колебания воды подо льдом пренебрегаемо малы, особенно это относится к морям (Белое, Карское, Лаптевых, Восточно-Сибирское). От побережья СЛО развивается сеть IV класса нивелирования, обеспечивающая точность определения нормальных высот точек, достаточную для создания топографических карт в масштабе 1:10 000 и 1:25 000.

Картографическое обеспечение Арктики. После создания и сгущения планово-высотной основы выполняется аэрофототопографическая съемка местности, в частности зоны береговой черты шельфа СЛО, отечественными фотоаппаратами с объективами «Руссар».

Для определения пространственных прямоугольных $X, Y, Z$ координат точек фотографирования аэроснимков используются системы спутниковой навигации GPS/ГЛОНАСС. Активно применяются интегральные навигационные комплексы типа IMU, определяющие значения шести элементов внешнего ориентирования каждого аэрофотоснимка (линейные и угловые).

Преобразование пространственных прямоугольных координат в плоские прямоугольные координаты и нормальные высоты $x, y, H^{\prime}$, необходимые для картографирования, производится по схеме

$$
\left[\begin{array}{l}
X \\
Y \\
Z
\end{array}\right] \Rightarrow\left[\begin{array}{l}
B \\
L \\
H
\end{array}\right] \Rightarrow\left[\begin{array}{l}
x \\
y \\
H^{\gamma}
\end{array}\right] .
$$

Топографические карты и планы составляются по известной методике. При необходимости создания цифровой топографической карты местности фотограмметрическую обработку результатов аэросъемки целесообразно выполнять с помощью отечественной фотограмметрической станции PHOTOMOD. Такая методика была внедрена ФГУП «Аэрогеодезия» в 2000-2003 годах на территории Норильского промышленного района (Арктики) при создании цифровых топографических карт масштаба 1:1000 [6].

Обновление нормативно-технической документации. Разработанная ранее нормативнотехническая документация по топографической съемке шельфа коренным образом устарела. Для возобновления топографического картографирования шельфа требуется ее переработка с учетом использования современных технических средств и методов.

В качестве технических средств определения плановых координат судна в основном используются приемники спутниковых систем GPS/ГЛОНАСС. В качестве технических средств определения высот применяют многолучевые эхолоты и современную гидроакустическую аппаратуpy $[3,13,14]$.

Нормативно-техническая документация по топографической съемке шельфа должна включать:

- основные положения по созданию картографических карт шельфа;

- инструкцию по топографической съемке шельфа;

- руководство по топографической съемке шельфа;

- образцы топографических карт шельфа;

- руководящие технические материалы;

- программные модули и др.

В качестве основы для разработки нормативно-технической документации возможно использование созданной в ЦНИИГАиК и ФГУП «Аэрогеодезия» в 1975-1992 годах аналогичной документации.

Исследования по определению внешней границы континентального шельфа в пределах полярных владений РФ. С геологической точки зрения внешняя граница континентального шельфа ограничивается бровкой - линией значительного перегиба поверхности рельефа шельфа, где проходит граница между шельфом и материковым склоном. При этом глубина бровки шельфа различна и не совпадает ни с одной из изобат. По данным американского ученого Ф.Шепарда, средняя глубина шельфа 132 м, его средняя ширина 78 км, а средний уклон $0,1^{\circ}$ [12]. Однако глубина и ширина шельфа значительно колеблются. В отдельных районах шельф простирается до глубины свыше 2 км, а его ширина местами, например в Северном Ледовитом океане, достигает 1,5 тыс.км. 
Топографро-геодезическое и картографическое обеспечение Арктической зоны...

Согласно юридическому определению Международной конвенции «О континентальном шельфе» (Женева, 1958 г.), зона шельфа ограничивается, как правило, 200-метровой изобатой или большей глубиной, на которой возможна разработка донных ресурсов. В некоторых государствах, однако, существуют другие определения внешней границы шельфа: по 500-метровой изобате, 200-мильному (370 км) удалению от берега и т.д. В настоящее время в практику введено понятие о расширенном шельфе. Более подробные сведения о границах шельфа изложены в работе [2]. В этой связи чрезвычайно актуальным является вопрос разграничения шельфовых зон СЛО между Россией, США, Канадой, Норвегией, Данией, Швецией. Одним из важных документов Заявки в ООН является результат площадной батиметрической съемки СЛО, оформленный в графической и цифровой форме [2, 8 и др.]. Авторы принимают активное участие в подготовке данной Заявки. Существенный вклад в решение данного вопроса имеет участие ОСШ в экспертной группе российской делегации при защите пересмотренных частичных заявок в отношении внешней границы континентального шельфа СЛО для передачи их в Комиссию по границам континентального шельфа при ООН.

Заключение. В представленной работе приведен обзор исследований с участием авторов в научно-исследовательских разработках по топографо-геодезическому и картографическому обеспечению сухопутной зоны Арктики и континентального шельфа морей Северного Ледовитого океана в пределах территорий РФ. Представлены новые разработки и пути практического их использования. Изложен вариант проекта топографо-геодезического и картографического обеспечения Арктической зоны РФ на основе использования современных технических средств и методов.

Значительная часть работы выполнена в рамках государственных заказов: техникоэкономический доклад «Состояние и задачи предприятий ГУГК по картографированию шельфа морей РФ», темы 07.962, 07.963, 07.911, 07.912, 07.914 и др.

Апробирование спутниковой технологии осуществлялось на двух пунктах фундаментальной астрономо-геодезической сети, функционирование которых обеспечивают АО «Аэрогеодезия» и ОСШ и на пунктах спутниковых сетей: высокоточной геодезической сети и СГС-1 (спутниковая геодезическая сеть) в Санкт-Петербурге (Пулково), его окрестностях и в Ленинградской области.

\section{ЛИТЕРАТУРА}

1. Алеева С.В. 70 лет полярной гидрографии. СПб: ООО «Фортекс групп»,2003. 248 с.

2. Анализ технологий для обеспечения батиметрических исследований Северного Ледовитого океана в интересах определения внешней границы континентального шельфа и опыт их применения / Ю.Г.Фирсов, В.Н.Баландин, И.В.Меньшиков, М.Г.Мустафин // Геодезия и картография. 2010. № 9. С. 54-59.

3. Арктический бассейн (геология и морфология) / Под ред. В.Д.Каминского. СПб: ВНИИОкеангеология, 2017. 291 с.

4. Баландин В.Н. Преобразование координат из одной системы в другую / В.Н.Баландин, И.В.Меньшиков, Ю.Г.Фирсов. СПб: ОАО «Петроцентр», 2016. 87 с.

5. Баландин В.Н. Радиогеодезические системы в аэросъемке. М.: Недра, 1983. 141 с.

6. Матвеев А.Ю. Опыт создания цифровых моделей местности и цифровых топографических планов на Норильский промышленный район // Геодезия и картография. 2005. № 4. С. 38-40.

7. О работе предприятий ГУГК по топографической съемке шельфа морей Северного Ледовитого океана в пределах Арктических владений России / И.В.Меньшиков, В.Н.Баландин, М.Я.Брынь, Ю.Г.Фирсов // Инновационные принципы устойчивого развития Арктических регионов: Труды Международного конгресса. СПб: Комитет по науке и высшей школе Правительства СПб. 2010. С. 22-24.

8. Петухов И.М. О формировании рельефа земной поверхности / И.М.Петухов, В.С.Сидоров, М.Г.Мустафин // Горный информационно-аналитический бюллетень (научно-технический журнал). 2006. № 4. С. 303-309.

9. Проблемные вопросы сдвижения горных пород / М.Г.Мустафин, С.Н.Зеленцов, Е.И.Кузнецова, А.А.Рожко // Записки Горного института. 2010. Т. 185. С. 227-230.

10. Решение задач геодезии и картографии в функциях пространственных прямоугольных координат / В.Н.Баландин, М.Я.Брынь, И.В.Меньшиков, Ю.Г.Фирсов, С.Л.Штерн. СПб: ОАО «Петроцентр», 2013. 94 с.

11. Спутниковые и традиционные геодезические измерения / В.Н.Баландин, М.Я.Брынь, В.Ф.Хабаров, А.В.Юськевич. СПб: ФГУП «Аэрогеодезия», 2003. 112 с.

12. Средства и методы топографической съемки шельфа / В.Н.Баландин, Л.А.Борисов, Р.Д.Володарский и др. М.: Недра, 1979. 295 с.

13. Фирсов Ю.Г. Инновационные гидрографические технологии для батиметрической съемки рельефа дна Северного Ледовитого океана в интересах определения внешней границы континентального шельфа Российской Федерации в Арктике / Ю.Г.Фирсов, В.Н.Баландин, И.В.Меньшиков // «Цели развития тысячелетия» и инновационные принципы устойчивого развития Арктических регионов: Материалы ІІІ Международного конгресса. СПб: «ООО «ПИФСОМ», 2010. С. 4-13.

14. Фирсов Ю.Г. Основы гидроакустики и использования гидрографических сонаров. СПб: Нестор История, 2010. 347 с. 
И.В.Меньшиков, Ю.Г.Фирсов

Топографро-геодезическое и картографическое обеспечение Арктической зоны...

Авторы: М.Г.Мустафин, д-р техн. наук, заведующий кафедрой, тиstafinm@таil.ru (Санкт-Петербургский горный университет, Санкт-Петербург, Россия), В.Н.Баландин, канд. техн. наук, ведущий научный сотрудник, bal8@yandex.ru (Федеральный научно-технический иентр геодезии, картографии и инфраструктуры пространственных данных, СанктПетербург, Россия), М.Я.Брынь, д-р техн. наук, заведующий кафедрой, kig@pgups.edи (Петербургский государственный университет путей сообщения, Санкт-Петербург, Россия), А.Ю.Матвеев, канд. техн. наук, генеральный директор, aero@agspb.ru (АО «Аэрогеодезия», Санкт-Петербург, Россия), И.В.Меньшиков, канд. техн. наук, руководитель, miv556@gmail.com (Федеральный научно-технический иентр геодезии, картографии и инфраструктуры пространственных данных, Санкт-Петербург, Россия), Ю.Г.Фирсов, канд. техн. наук, ведущий научный сотрудник, gidrograph@таіl.ru (Федеральный научно-технический иентр геодезии, картографии и инфраструктуры пространственных данных, СанктПетербург, Россия).

Статья поступила в редакциию 27.10.2017.

Статья принята к публикации 04.04.2018. 